\title{
Assessment of process parameters influencing the enhanced production of prodigiosin from Serratia marcescens and evaluation of its antimicrobial, antioxidant and dyeing potentials
}

\author{
Chandni Gulani, Sourav Bhattacharya ${ }^{*}$ and Arijit Das \\ Department of Microbiology, Genohelix Biolabs, A Division of Centre for Advanced Studies in Biosciences, Jain \\ University.127/3, Bull Temple Road, Chamarajpet, Bangalore - 560019, Karnataka, India. \\ E-mail: sourav3011@rediffmail.com
}

Received 2 November 2011; Received in revised form 27 January 2012; Accepted 27 January 2012

\begin{abstract}
Aims: Prodigiosin is a bright red pigment produced by certain strains of Serratia marcescens, characterized by a common pyrrolylpyrromethane skeleton. This pigment is found to possess antibacterial, antifungal, immunosuppressive and antiproliferative activity. The present study aimed at designing process parameters for the enhanced production of this pigment.

Methodology and Results: Peptone glycerol broth was selected as the best synthetic medium. The effects of various media components and process parameters like carbon and nitrogen sources, temperature, $\mathrm{pH}$, incubation period and other supplements were investigated. Maximal amount of prodigiosin was produced at temperature $25^{\circ} \mathrm{C}, \mathrm{pH} 7.0$ and incubation period of $48 \mathrm{~h}$. Supplementation of media with maltose and peptone yielded maximal amount of prodigiosin. Incorporation of minimal amount of supplements like silica gel, iron salts, inorganic phosphate also showed promising results. Chromatographic separations suggested that prodigiosin is made up of three different fractions (purple, orange and red). Further investigation of antimicrobial properties of prodigiosin revealed that it is a potent inhibitor against gram positive bacteria like Staphylococcus aureus and Bacillus cereus and fungal pathogens like Candida albicans, C. parapsilosis and Cryptococcus sp. This antimicrobial potency remained stable under a wide range of temperature and $\mathrm{pH}$. The antioxidant capacity of prodigiosin was found to be $22.05 \mu \mathrm{g}$ ascorbic acid equivalents $/ \mathrm{ml}$ of extract. When applied to textiles, prodigiosin resisted the action of acid, alkali and detergent.

Conclusion, Significance and Impact of study: Besides combating gram positive bacterial pathogens and some pathogenic yeasts, prodigiosin with strong dyeing and antioxidant activity may find broad applications in textile and therapeutic industries.
\end{abstract}

Keywords: Serratia marcescens, antimicrobial, antioxidant, biopigment, prodigiosin

\section{INTRODUCTION}

Natural products either synthesized or secreted by organisms represent one of the critical sources of potential medicinal use. One of these natural products is the small molecular weight compounds secreted by organisms having no demonstrable function in the cells and known as secondary metabolite. They have a major effect on the health, nutrition and economics of our society. There are several organisms which can produce pigments, which are one of the important classes of these secondary metabolites and are often referred to as biopigments. These biopigments can be obtained from two major sources, plants (Papageorgiou et al., 1979) and microorganisms (Cho et al., 2002). Biopigments from the micro-organisms have been preferred over those from plants because of their stability (Raisainen et al., 2002) and the availability of their cultivation technology (Kim et al., 1999; Parekh et al., 2000) throughout the year. On the other hand, biopigments from plants have numerous drawbacks like instability against light, heat or adverse
$\mathrm{pH}$, low water solubility and often non-availability throughout the year.

One of the studied biopigments of microbial origin is the prodigiosin. Prodigiosins are a family of natural red pigments, characterized by a common pyrrolylpyrromethane skeleton, having low molecular weight (323.4 Dalton), appearing only in the late stages of bacterial growth. Prodigiosin $\left(\mathrm{C}_{20} \mathrm{H}_{25} \mathrm{~N}_{3} \mathrm{O}\right)$ is produced by many strains of the bacterium Serratia marcescens, and other gram negative bacteria and some other unrelated microbial strains, such as Vibrio psychroerythrus, Streptomyces griseoviridis, and Hahella chejuensis (Hubbard and Rimington, 1950), where it has been shown to be associated with extracellular vesicles or present in intracellular granules (Kobayashi and Ichikawa, 1991; Matsuyama et al., 1986). It has been discovered that prodigiosin possesses antibacterial, antifungal, antiprotozoal (Croft et al., 2002), cytotoxic (Nakashima et al., 2005) antitumor (Perez-Tomas et al., 2003), antimalarial, antidiabetic, nonsteroidal and antiinflammatory properties. In light of its potential commercial

*Corresponding author 
values, there is a demand to develop high throughput and cost effective bioprocesses for prodigiosin production.

The present investigation focuses on the optimization of cultural parameters to achieve the enhanced production of prodigiosin from $S$. marcescens, followed by its chromatographic analysis. Exploration of the antimicrobial, antioxidant and dyeing properties of prodigiosin were also important criteria of the study. To our knowledge this is the first report on the effect of various temperatures and $\mathrm{pH}$ on the antimicrobial potency of the pigment.

\section{MATERIALS AND METHODS}

\section{Isolation and identification of S. marcescens}

For isolation of $S$. marcescens, swab sample was collected from a toilet water pipe, serially diluted and plated on nutrient agar and incubated at $37^{\circ} \mathrm{C}$ for $24 \mathrm{~h}$. Following incubation, red coloured colonies were selected and propagated on the same medium until pure cultures were obtained. Pigmentation of the colonies and Gram's staining results followed by standard biochemical characterization confirmed that the colonies were of $S$. marcescens. Pure culture was maintained on nutrient agar slants in duplicates and stored at $4{ }^{\circ} \mathrm{C}$ until used.

\section{Selection of the media for the maximal production of prodigiosin by $S$. marcescens}

In order to determine the media supporting the maximal production of prodigiosin, S. marcescens was grown in different media (nutrient broth, peptone glycerol broth, gelatin broth, LB broth, tryptone yeast extract broth, yeast extract malt extract broth, glycerol beef extract broth and tryptone soya broth) at $37^{\circ} \mathrm{C}$ for $24 \mathrm{~h}$.

\section{Confirmation and quantification of prodigiosin}

Bacterial cell absorbance in the broths was measured at $620 \mathrm{~nm}$, following which the broth suspensions were subjected to centrifugation at $5000 \times \mathrm{g}$ for $15 \mathrm{~min}$ to collect the cell pellet. $10 \mathrm{~mL}$ of $95 \%$ methanol was added to the cell pellet and centrifuged under the same condition. Debris was removed and the $2 \mathrm{~mL}$ of the supernatant was taken in two test tubes. The content of one of the test tube was acidified with a drop of concentrated $\mathrm{HCl}$ and the other alkalinized with a drop of concentrated ammonia solution. A red or pink colour in the acidified solution and a yellow or tan colour in the alkaline solution indicated a positive, presumptive test for prodigiosin (Gerber and Lechevalier, 1976). $5 \mathrm{~mL}$ of the supernatant was subjected to spectrum scanning in the range of 300 to 700 $\mathrm{nm}$ using a SANYO Gallenkamp UV-VIS spectrophotometer (UK). 95\% methanol was used as a blank. Methanolic extract of prodigiosin showed characteristic maxima at $499 \mathrm{~nm}$. Extracted prodigiosin was estimated using the following equation (Mekhael and Yousif, 2009).

Prodigiosin unit/cell $=\left(\left[\mathrm{OD}_{499}-\left(1.381 \times \mathrm{OD}_{620}\right)\right]\right) \times 1000 / \mathrm{OD}_{620}$
Where, $\mathrm{OD}_{499}$ - pigment absorbance

$\mathrm{OD}_{620}$ - bacterial cell absorbance

1.381 - constant

Optimization of the parameters for maximal production of prodigiosin

Media optimization was done to standardize the conditions favouring the maximal production of prodigiosin by $S$. marcescens. The selected media which yielded the maximum amount of prodigiosin was varied with different carbon sources $(1 \% \mathrm{w} / \mathrm{v}$ : sucrose, fructose, lactose, mannitol, glucose and maltose), nitrogen sources (1\% $\mathrm{w} / \mathrm{v}$ : tryptone, ammonium chloride, ammonium sulphate, urea, ammonium oxalate, ammonium nitrate, ammonium acetate, yeast extract and peptone).

Effect of different concentrations of inorganic salts like $\mathrm{NaCl}(0.25,0.5,1.0,1.5,2.0,3.0$ and $4.0 \%), \mathrm{FeCl}_{3}(1,2$, 3,4 , and $5 \mu \mathrm{g} / \mathrm{mL}$ of media) and $\mathrm{K}_{2} \mathrm{HPO}_{4}(0.1,0.3,0.5,1$ and $10 \mathrm{mM}$ ) were examined. The effect of silica gel was being studied by amending its various concentrations into the media $(2,4,6,8$ and $10 \mathrm{mg}$ silica $\mathrm{gel} / \mathrm{mL}$ of media).

In order to determine the effect of physical parameters on the maximal production of prodigiosin, $S$. marcescens was grown at various $\mathrm{pH}(5,6,7,8,9$ and 10), temperature $\left(20,25,30,35\right.$ and $\left.40^{\circ} \mathrm{C}\right)$.

\section{Separation of prodigiosin fractions by Thin Layer Chromatography}

The CFS was put in a separating funnel and double the volume of petroleum ether was added. The separating funnel was shaken vigorously for 10-15 min allowing the two liquids to separate. Prodigiosin was extracted in the petroleum ether layer which was removed carefully from the separating funnel. This petroleum ether layer was poured in a petri dish and kept at $30^{\circ} \mathrm{C}$ to $40{ }^{\circ} \mathrm{C}$ in order to evaporate the solvent completely, following which $2 \mathrm{~mL}$ of $95 \%$ methanol was added. The methanolic extract of prodigiosin was stored in a sterile container.

Methanolic extract of prodigiosin was separated by the solvent system containing methanol, ethyl acetate and chloroform in the ratio of $6: 3: 1(\mathrm{v} / \mathrm{v})$. $10 \mu \mathrm{L}$ of methanolic extract of prodigiosin was loaded on to the silica gel slides and run against the solvent till the solvent front reaches $2 / 3^{\text {rd }}$ of the slide. After the development of the chromatograms, slides were removed and dried. The retardation factor (Rf) values of the chromatogram were calculated (Lynch et al., 1968).

\section{Evaluation of in vitro antimicrobial activity of prodigiosin}

The antimicrobial activities of prodigiosin were studied on Mueller Hinton agar by the disc diffusion technique against clinical isolates of Bacillus cereus, Staphylococcus aureus, Escherichia coli, Pseudomonas aeruginosa, 
Candida albicans, C. parapsilosis and Cryptococcus sp. maintained in the Department of Microbiology, Genohelix Biolabs, Bangalore.

Sterile filter paper discs $(6 \mathrm{~mm})$ were individually impregnated with $50 \mu \mathrm{L}$ of methanolic extract of prodigiosin. $95 \%$ methanol was taken as control. All the discs were dried and placed on the surface of the test bacterial and fungal lawn. Following 18 to $24 \mathrm{~h}$ of incubation at $37{ }^{\circ} \mathrm{C}$ the plates were examined for the zones of inhibition.

\section{Effect of temperature treatment on inhibitory activity} of prodigiosin

Methanolic extracts of prodigiosin were exposed to different temperatures $\left(30,50\right.$ and $80^{\circ} \mathrm{C}$ for $30 \mathrm{~min}$ and at $121{ }^{\circ} \mathrm{C}$ for $15 \mathrm{~min}, 15 \mathrm{lbs}$ pressure). A control was maintained by incubating methanolic extract at $37^{\circ} \mathrm{C}$. Antimicrobial activity was performed as mentioned earlier.

\section{Effect of pH on inhibitory activity of prodigiosin}

The sensitivity of prodigiosin to different $\mathrm{pH}$ was estimated by adjusting the $\mathrm{pH}$ of the methanolic extracts for $30 \mathrm{~min}$ to $\mathrm{pH} 2,4,6,8,10$, and 12 by using $1 \mathrm{~N} \mathrm{HCl}$ or $1 \mathrm{~N}$ $\mathrm{NaOH}$. A control was maintained by adjusting the methanolic extract of prodigiosin to neutral $\mathrm{pH}$. Antimicrobial activity was performed.

\section{Total antioxidant capacity}

The total antioxidant capacity of the methanolic extract was evaluated by phosphomolybdenum method (Prieto et al., 1999). $0.1 \mathrm{~mL}$ of the extract solution was mixed with 1 $\mathrm{mL}$ reagent solution (6 M sulfuric acid, $28 \mathrm{mM}$ sodium phosphate and $4 \mathrm{mM}$ ammonium molybdate). The reaction mixture was incubated at $95{ }^{\circ} \mathrm{C}$ for $90 \mathrm{~min}$. The absorbance of the solution was spectrophotometrically measured at $695 \mathrm{~nm}$ using a blank. The antioxidant capacity of the extract was evaluated as equivalents ascorbic of acid ( $\mu \mathrm{g} \mathrm{AE} / \mathrm{mL}$ extract)

\section{Effectiveness as dyeing agent}

$1 \mathrm{~cm}^{2}$ of each fabric (wool, silk, nylon, cotton and polyester) was soaked in $2 \mathrm{~mL}$ methanolic extract of prodigiosin taken in different test tubes and incubated for $48 \mathrm{~h}$ at room temperature, following which each fabric was dried and cut into 5 smaller pieces. These smaller pieces were then treated with acid, alkali, cold water, cold water and detergent and hot water and detergent for $1 \mathrm{~h}$ in respective test tubes.

\section{RESULTS AND DISCUSSION}

Biopigments produced by bacteria possess enormous efficiency as medicinally important products. Prodigiosin, a red pigment synthesized by $S$. marcescens, belongs to the family of tripyrrole and exhibits antimicrobial, immunomodulating and anti-tumor properties. The present investigation focused on formulation of a production medium for effective prodigiosin production and separation of the pigment followed by its antimicrobial activity evaluation.

\section{Selection of synthetic media}

Peptone glycerol broth was found to be suitable medium for prodigiosin production (763.55 prodigiosin unit/cell) by $S$. marcescens (Figure 1). This result is in perfect agreement with the previous results where enhanced pigment production was observed in the glycerol broth at $30{ }^{\circ} \mathrm{C}$ over nutrient broth at $28{ }^{\circ} \mathrm{C}$ (Giri et al., 2004). Hejazi and Falkiner, 1997 also reported the highest increase in biomass and maximal pigmentation in cultures grown on glycerol medium

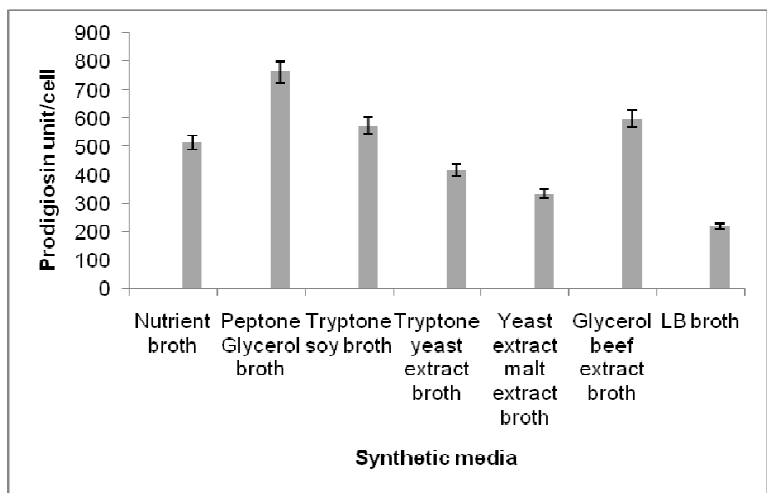

Figure 1: The effect of synthetic media on prodigiosin production

\section{Effect of carbon sources}

Different sugars when added to the peptone glycerol medium, the maximum amount of pigment production was observed in the presence of maltose (784.15 prodigiosin unit/cell), followed by moderate level of pigment production in medium amended with lactose, fructose and sucrose and the least being in the medium amended with mannitol (Figure 2). A similar result was observed, wherein a new strain designated as $S$. marcescens NY1 yielded $425 \pm 40 \mathrm{mg} / \mathrm{L}$ of prodigiosin which is maximum of all sugars tested, when maltose was amended in the media. Moderate level of pigment production was observed in medium amended with lactose and sucrose (Sundaramoorthy et al., 2009). The role of glucose in pigment production is critical. Our study revealed that glucose when incorporated in the media resulted in decreasing the pigment production which is in accordance the previous investigations (Oller, 2005; Clements-Jewery, 1976).

\section{Effect of nitrogen sources}

Study regarding the effect of nitrogen source on the prodigiosin production, revealed that Serratia marcescens proliferated and produced maximum pigment (793.48 
prodigiosin unit/cell) in the presence of peptone (Figure 3), whereas, pigmentation was delayed in media amended with urea and ammonium oxalate. The organism failed to grow in the media supplemented with ammonium chloride, ammonium sulphate, ammonium nitrate and ammonium acetate, possibly indicating the toxicity of ammonium salts towards the organism. Previously, S. marcescens grown on mineral media did not produce pigment when the carbon source was glucose or the nitrogen source was ammonium chloride (Hejazi and Falkiner, 1997).

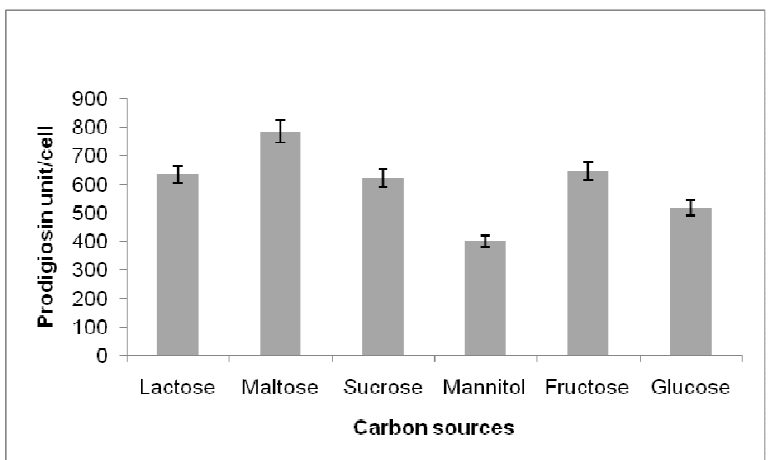

Figure 2: The effect of carbon sources on prodigiosin production

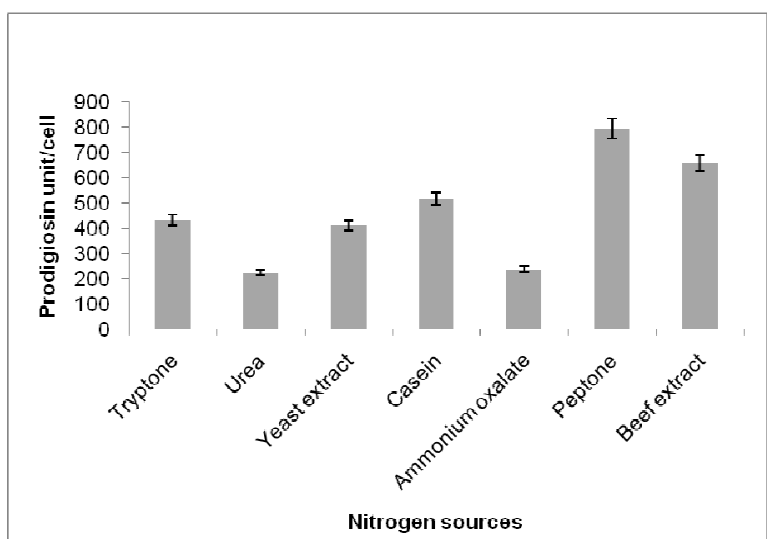

Figure 3: The effect of nitrogen sources on prodigiosin production

\section{Effect of inorganic salts}

$0.25 \%$ of $\mathrm{NaCl}$ supported the maximal pigment production and there was a decline in the production with the increase in the \% of $\mathrm{NaCl}$ (being the minimal at $4.0 \%$ of $\mathrm{NaCl}$ ). This result was at par with that obtained by Silverman and Munoz, 1973, who studied the effect of $\mathrm{NaCl}$ in two strains of $S$. marcescens- wild-type 264 and wild-type Nima and observed that both strains showed decrease in the prodigiosin synthesis per unit of cell mass at higher $\mathrm{NaCl}$ concentrations, often reaching complete inhibition at salt concentrations varying between 0.5 to 3.0 $\% \mathrm{NaCl}$ in strain 264 and 2.5 to $3.0 \% \mathrm{NaCl}$ in strain Nima.
Moreover, in the present study, high \% of $\mathrm{NaCl}(4 \%)$ favoured the growth of the white mutants of the bacteria, inhibiting the production of prodigiosin completely.

Iron salt, inorganic phosphate and silica gel enhanced the pigment production when amended in the medium in minimal amount. This result is in contradiction with an earlier study, where it was found that $8 \mathrm{mg} / \mathrm{mL}$ of silica gel when amended in the liquid peptone glycerol media yielded the maximal amount of prodigiosin (Yamashita et al., 2001). A high elevation of pigment formation was obtained in the media amended with $0.1 \mathrm{mM}$ of inorganic phosphate. As the concentration of inorganic phosphate increases, the ability of $S$. marcescens to produce the prodigiosin decreases. A high elevation in pigment formation at less than or equal to $0.3 \mathrm{mM} \mathrm{Pi}$ by $S$. marcescens supports our study (Witney et al., 1977).

\section{Effect of pH on pigment production}

For the selected isolate of Serratia, the maximum prodigiosin yield (811.88 prodigiosin unit/cell) was observed at $\mathrm{pH}$ of 7.0 (Figure 4). $\mathrm{pH}$ of the media plays a very crucial role in the synthesis of secondary metabolites and therefore affects the biosynthesis of prodigiosin. Maximum amount of prodigiosin by a new strain designated as $\mathrm{S}$. marcescens $\mathrm{NY} 1$ was produced at $\mathrm{pH}$ 7.0 (Sundaramoorthy et al., 2009). Moreover, studies revealed that the inhibitory effect of carbon sources on prodigiosin production may be due to a lowering of the $\mathrm{pH}$ of the medium (Sole et al., 1997). This suggests the importance of $\mathrm{pH}$ in the media since its altered value can either increase or decrease the amount of prodigiosin.

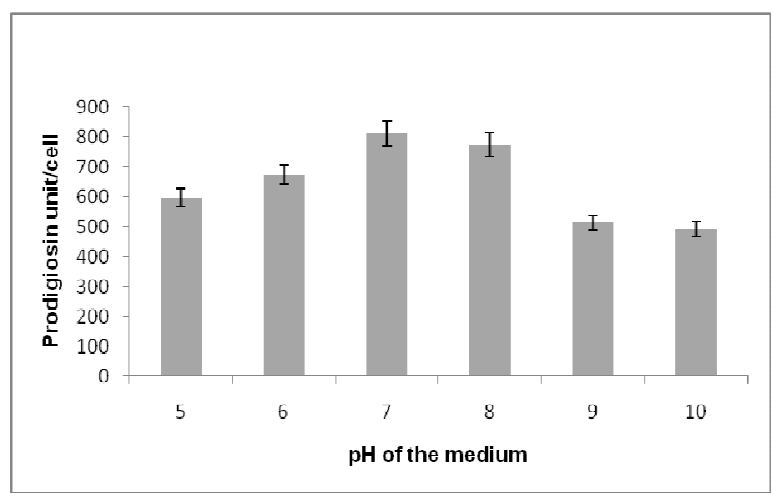

Figure 4: The effect of media $\mathrm{pH}$ on prodigiosin production

\section{Effect of temperature on pigment production}

In a synthetic media comprising of maltose, peptone, $\mathrm{NaCl}$ and glycerol, the maximal prodigiosin (709.29 prodigiosin unit/cell) was obtained at a temperature of $25^{\circ} \mathrm{C}$ (Figure $5)$. A survey on the role of the temperature and incubation time on the pigment synthesis implies that these are important physical factors which decide the prodigiosin production depending on the type of media. Biosynthesis 
of prodigiosenes (prodigiosin and prodigiosin like pigments) by $S$. marcescens occurred over a relatively narrow range of temperatures with maximal production being between 24 and $28{ }^{\circ} \mathrm{C}$, although the bacteria grow over a broad range of temperature (Williams, 1973). However, peptone glycerol broth gave the maximum amount of prodigiosin at $30^{\circ} \mathrm{C}$ (Giri et al., 2004).

In the present study, a complete block in the prodigiosin production was observed when $S$. marcescens was incubated at $35^{\circ} \mathrm{C}$ or above characterized by the growth of white mutants of Serratia which did not synthesize prodigiosin. Reduction in the pigment production at elevated temperatures is well documented (Sundaramoorthy et al., 2009; Pryce and Terry, 2000).

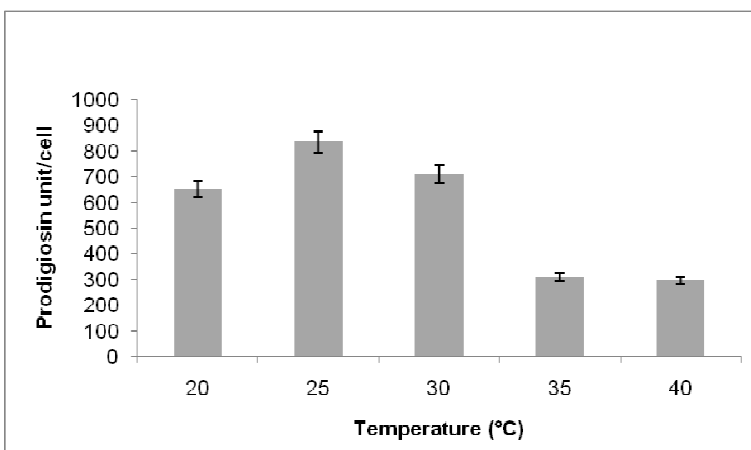

Figure 5: The effect of temperature on prodigiosin production

\section{Thin Layer Chromatography}

Three different fractions, characterized by purple, red and orange bands were obtained with $\operatorname{Rf}$ of $0.27,0.64$ and 0.82 respectively, when the methanolic extract of prodigiosin was run against a mixture of methanol: ethyl acetate: chloroform in the ratio of $6: 3: 1(\mathrm{v} / \mathrm{v})$, as indicated in Table 1. It was observed that purple fraction was the first to be separated followed by orange and red fractions. The orange component was found to be unstable and got merged with the red component very rapidly soon after the separation as suggested in previous report (Bunting, 1940; Weiss, 1949).

Similar results as that of the present study were obtained by Williams et al. (1956), who developed the circular chromatogram in which acetone-extracted prodigiosin was separated into at least four bands- blue, red, red and orange at $\operatorname{Rf} 0.18,0.48,0.70$ and 0.89 . The orange band at $\mathrm{Rf} 0.89$ has only an evanescent orange colour which rapidly turns red when exposed to air. A blue band at $R f$ 0.18 is consistently present. The presence of this blue component was suggested in previous reports (Bunting, 1940; Weiss, 1949) since they had observed a slowmoving purple band in their chromatograms of prodigiosin. The purple band was probably the same blue component reported here, but admixed with red fractions.
Table 1: Rf values of different fraction of methanolic extract of prodigiosin

\begin{tabular}{ll}
$\begin{array}{l}\text { Fractions of methanolic extract of } \\
\text { prodigiosin }\end{array}$ & Rf value \\
\hline Purple & 0.217 \\
Red & 0.64 \\
Orange & 0.82 \\
\hline
\end{tabular}

\section{In vitro antimicrobial potency}

By the use of disc-agar diffusion technique, it was observed that the prodigiosin was able to inhibit majority of the test bacteria. As indicated in Table 2, the inhibitory zones for bacteria varied between $10.5 \pm 0.47 \mathrm{~mm}$ and $17.5 \pm 0.47 \mathrm{~mm}$, whereas, fungicidal activity was evident from the clear zones of inhibition observed against $C$. parapsilosis and Cryptococcus sp. Fungistatic activity was observed against C. albicans. Prodigiosin possesses antibacterial activity against gram positive bacteria like Staphylococcus species and not against gram negative bacteria like E.coli and Pseudomonas species. The fungal pathogens being sensitive to this potent antimicrobial agent were the $C$. parapsilosis, Cryptococcus sp. and to a lesser extent $C$. albicans (Khanafari et al., 2006).

Table 2: Antimicrobial activity of prodigiosin

\begin{tabular}{lc}
\hline Pathogens & Zone of inhibition $(\mathrm{mm})$ \\
\hline S. aureus & $17.5 \pm 0.47$ \\
B. cereus & $10.5 \pm 0.47$ \\
E. coli & - \\
P. aeruginosa & $11.3 \pm 0.47$ \\
Cryptococcus sp. & $15.0 \pm 0.81$ \\
C. parapsilosis & \\
\hline
\end{tabular}

\section{Effect of temperature and $\mathrm{pH}$ on antimicrobial activity} of prodigiosin

The biocidal activities of prodigiosin have been already identified in vitro conditions; however, there is no report illustrating the stability of the antimicrobial potency of prodigiosin when exposed to different temperature and $\mathrm{pH}$ variations. The antimicrobial property of the methanolic extract of prodigiosin was relatively stable during heat treatments at $30,50,80$ and $121{ }^{\circ} \mathrm{C}$ for a given time period. Treatment of the culture supernatants at these temperatures did not show significant difference from the control. Similar to the effect of temperature, the antimicrobial activity of the culture supernatants after treatment at different tested $\mathrm{pH}$ was not significantly affected. Prodigiosin showed better antimicrobial activity at the acidic $\mathrm{pH}$ than the basic $\mathrm{pH}$. The highest zone of inhibition was at $\mathrm{pH} 6(16.0 \pm 0.31 \mathrm{~mm})$ and the lowest $(9.0 \pm 0.24 \mathrm{~mm})$ at $\mathrm{pH} 2$ and $\mathrm{pH} 12$. To the best of our knowledge this study provides the first scientific record regarding the relation between prodigiosin and the stability of its antimicrobial property under different temperature and $\mathrm{pH}$ range. 


\section{Total antioxidant capacity}

Total antioxidant capacity was reported as ascorbic acid equivalents. The total antioxidant capacity of the methanolic extract was $22.05 \mu \mathrm{g} \mathrm{AE} / \mathrm{mL}$. There is a little information about total antioxidant activity of prodigiosin by phosphomolybdate method which employs costeffective reagents. It is based on the reduction of Mo (VI) to Mo (V) in presence of antioxidant compound and subsequent formation of a green phosphate/Mo (V) complex at acidic $\mathrm{pH}$ and at higher temperature.

\section{Prodigiosin as textile colourant}

It was observed that when the different fabrics (wool, silk, nylon, cotton and polyester) were subjected to the treatment with acid, alkali, cold water, hot water, cold water and detergent and hot water and detergent for $1 \mathrm{~h}$, the colour of the dye for all the fabrics was completely retained in cases of acid and cold water treatments whereas a small amount of discolouration resulted when treated with alkali, cold water and detergent and hot water and detergent.

\section{CONCLUSION}

This study demonstrated a successful optimization of the cultural parameters that facilitated the enhanced production of the prodigiosin. The antimicrobial and antioxidant potential of the pigment may aim at the possible future usage of prodigiosin as a therapeutic. Prodigiosin being resistant to acid, alkali and detergents may be explored further as a colourant in the textile industry.

\section{ACKNOWLEDGEMENTS}

We wish to extend our sincere gratitude to Dr. Chenraj Jain, Chairman, Jain Group of Institutions, Bangalore, India, for providing us with all the financial and laboratory facilities required for this research work. We also wish to thank Dr. Gopal Krishna Sahu, Head of the Department, M.A.T.S School of Life Sciences, Raipur, India and the entire supporting staff of Genohelix Biolabs, whose help has been invaluable for the successful completion of our research work.

\section{REFERENCES}

Bunting, M. I. (1940). A description of some color variants produced by Serratia marcescens, strain 274 . Journal of Bacteriology 40: 57-68.

Cho, Y. J., Park, J. P., Hwang, H. J., Kim, S. W., Choi, J. W. and Yun, J. W. (2002). Production of red pigment by submerged culture of Paecilomyces sinclairii. Letters in Applied Microbiology 35: 195-202.

Clements-Jewery, S. (1976). The reversal of glucose repressed prodigiosin Serratia marcescens marcescens. Science and Technology, Transaction of Missouri Academy of Science 2: 243-246. production in Serratia marcescens by the cyclic 3'5'adenosine monophosphate inhibitor theophylline. Experientia 15: 421-422.

Croft, S. L., Seifert, K. and Duchene, M. (2002). Antiprotozoal activities of phospholipid analogues. Molecular and Biochemical Parasitology 126: 165172.

Gerber, N. N. and Lechevalier, M. P. (1976). Prodiginine (prodigiosin-like) pigments from Streptomyces and other Actinomyces. Canadian Journal of Microbiology 22: 658-667.

Giri, A. V., Anandkumar, N., Muthukumaran, G. and Pennathur, G. (2004). A novel medium for the enhanced cell growth and production of prodigiosin from Serratia marcescens isolated from soil. $B M C$ Microbiology 4: 1- 10.

Hejazi, A. and Falkiner, F. R. (1997). Serratia marcescens. Journal of Medical Microbiology 46, 903-912.

Hubbard, R. and Rimington, C. (1950). The biosynthesis of prodigiosin, the, tripyrrylmethene pigment from Bacillus prodigiosus (Serratia marcescens). Biochemical Journal 46: 220-225.

Khanafari, A., Assadi, M. M. and Fakhr, F. A. (2006). Review of prodigiosin pigmentation in Serratia marcescens. Online Journal of Biological Science 6: 1-13.

Kim, C. H., Kim, S. W., Hong, S. I. (1999). An integrated fermentation separation process for the production of red pigment by Serratia sp. KH-95. Process Biochemistry 35: 485-490.

Kobayashi, N. and Ichikawa, Y. (1991). Separation of the prodigiosin localizing crude vesicles which retain the activity of protease and nuclease in Serratia marcescens. Microbiology and Immunology 35: 607614.

Lynch, D. L., Worthy, T. E. and Kresheck, G. C. (1968). Chromatographic separation of the pigment fractions from a Serratia marcescens strain. Applied Microbiology 16: 13-20.

Matsuyama, T., Murakami, T., Fujita, M., Fujita, S. and Yano, T. (1986). Extracellular vesicle formation and biosurfactant production by Serratia marcescens. Journal of General Microbiology 132: 865-875.

Mekhael, R., Yousif, S. Y. (2009). The role of red pigment produced by Serratia marcescens as antibacterial and plasmid curing agent. Journal of Duhok University 12: 268-274.

Nakashima, T., Tamura, T., Kurachi, M., Yamaguchi, K. and Oda, T. (2005). Apoptosis-mediated cytotoxicity of prodigiosin-like red pigment produced by gammaProteobacterium and its multiple bioactivities. Biological and Pharmaceutical Bulletin 28: 22892295.

Oller, A. R. (2005). Media effects of sugars on pigmentation and antibiotic susceptibility in Serratia

Papageorgiou, V. P., Winkler, A., Sagredos, A. N. and Digenis, G. A. (1979). Studies on the relationship of 
structure to antimicrobial properties of naphthoquinones and other constituents of Alkanna tinctoria. Planta medica 35: 56-60.

Parekh, S., Vinci, V. A. and Strobel, R. J. (2000). Improvement of microbial strains and fermentation processes. Applied Microbiology and Biotechnology 54: 287-301.

Perez-Tomás, R., Montaner, B., Llagostera, E. and Soto- Cerrato, V. (2003). The prodigiosins, proapoptotic drugs with anticancer properties. Biochemical Pharmacology_66: 1447-1452.

Prieto, P., Pineda, M. and Aguilar, M. (1999). Spectrophotometric quantitation of antioxidant capacity through the formation of a phosphor molybdenum complex: specific application to the determination of vitamin E. Analytical Biochemistry 269: 337-341.

Pryce, L. H. and Terry, F. W. (2000). Spectrophotometric assay of gene expression: Serratia marcescens pigmentation. Bioscience 26: 3-13.

Raisainen, R., Nousiainen, P. and Hynninen, P. H. (2002). Dermorubin and 5-chlorodermorubin natural anthraquinone carboxylic acids as dyes for wool. Textile Research Journal 72: 973-976.

Silverman, M. P. and Elaine, F. M. (1973). Effect of iron and salt on prodigiosin synthesis in Serratia marcescens. Journal of Bacteriology 114: 999-1006.

Sole, M., Francia, A., Rius, N. and Loren, J.G. (1997). The role of $\mathrm{pH}$ in the 'glucose effect' on prodigiosin production by non-proliferating cells of Serratia marcescens. Letters in Applied Microbiology_25: 8184.

Sundaramoorthy, N., Yogesh, P. and Dhandapani, R. (2009). Production of prodigiosin from Serratia marcescens isolated from soil. Indian Journal of Science and Technology 2: 32-34.

Weiss, C. M. (1949). Spectrophotometric and chromatographic analyses of the pigment produced by members of the genus Serratia. Journal of Cellular and Comparative Physiology 34: 467-492.

Williams, R. P., Green J. A. and Rappoport, D. A. (1956). Studies on pigmentation of Serratia marcescens. I. Spectral and paper chromatographic properties of prodigiosin. Journal of Bacteriology 71 : 115-120.

Williams, R. P. (1973). Biosynthesis of Prodigiosin, a secondary metabolite of Serratia marcescens. Applied Microbiology 25: 396-402.

Witney, F. R., Failia, M. L. and Weinberg, E. D. (1977). Phosphate inhibition of secondary metabolism in Serratia marcescens. Applied and Environmental Microbiology 33: 1042-1046.

Yamashita, M., Nakagawa, Y., Li, H. and Matsuyama, T. (2001). Silica gel-dependent production of prodigiosin and serrawettins by Serratia marcescens in a liquid culture. Environmental Microbiology 16: 250-254. 